\title{
Development and application of a soil classification-based conceptual catchment-scale hydrological model
}

\author{
$\underline{\text { D. Maréchal }}{ }^{1}$ and I.P. Holman $\bowtie$ \\ Institute of Water and Environment, Cranfield University, Silsoe, Bedford, MK45 4DT, UK
}

Corresponding author, Tel.: +44-1525-863252 Fax: +44-1525-863344 E-mail address : i.holman@cranfield.ac.uk

${ }^{1}$ Now at EQECAT, 16 Rue Drouot 75009 Paris, France

\begin{abstract}
A conceptual, continuous, daily, semi distributed catchment-scale rainfall-runoff model that has the potential to be ultimately used in ungauged catchments is described. The Catchment Resources and Soil Hydrology (CRASH) model is developed from the basis that the transformation of rainfall into simulated river discharge can be parameterised using pre-existing national datasets of soil, land use and weather; and that the spatial variability in soil properties and landuse are important to the hydrological response of a catchment and should be incorporated into the catchment representation. Both infiltration-excess and saturation-excess runoff mechanisms are simulated, with water movement through each soil layer simulated using a capacitance approach limited according to layer physical properties. The hydrological linkage between the response unit and catchment is parameterised using the existing national Hydrology of Soil Types (HOST) classification. The HOST classification groups all UK soil types into one of 29 hydrological classes for which nationally calibrated values of Base Flow Index and Standard Percentage Runoff are provided. CRASH has been calibrated and validated for three catchments in England with contrasting soil characteristics and meteorological conditions. The model was successful at simulating time series and flow duration curves in all catchments during the calibration and validation periods. The next development stage will be to test CRASH for a large
\end{abstract}


number of catchments covering a wider range of soils, land uses and meteorological conditions, in order to derive a set of regionalised model parameters based upon the HOST classification. The successful cross-scale linkage between water movement through the response unit and the catchmentscale hydrological response using the HOST classification, which incorporates the scale effects between plot and catchment, suggests that such national soil hydrological classifications may provide a sound and consistent framework for hydrological modelling in both gauged and ungauged catchments which should be extended to other regions.

\section{Keywords}

Rainfall-runoff model, conceptual model, classification, ungauged catchment, semi-distributed model, soil hydrology 


\section{Introduction}

Rainfall-runoff models can be used to investigate various hydrological issues relevant to environmental managers and decision-makers. Their use can, however, be restricted by the availability and quality of input and parameterisation data. One approach to tackle the challenge of modelling river flows in ungauged catchments appeared with the blue-print for a physically-based, distributed catchment model by Freeze and Harlan (1969). The Système Hydrologique Européen (SHE) system was developed following such a blue-print (Abbott et al. 1986) and was presented in opposition to lumped parameter models that "depend essentially on the availability of sufficiently long meteorological and hydrological records for their calibration" (Abbott et al.1986). However the use of physically-based, distributed models has since been questioned because of the actual significance of the parameters and the great amount of physical characteristics they require (Beven 1989).

It is generally agreed that the level of complexity of physically-based models is excessive for many practical problems. Jakeman and Hornberger (1993) stated that a simpler structure based on a slowflow component and a quick-flow component is sufficient for many purposes. Such conceptual models use simplified representations of the component processes which they do not try to fully represent with physically-based equations, but are generally optimised using observed streamflow data.

However, because they incorporate many fewer parameters, approaches have been developed to apply conceptual models in ungauged catchments. The most widely used method relates the model parameters to physical descriptors of the catchments (e.g. Sefton and Howarth, 1998; Seibert, 1999). The procedure of calibration has two stages. Firstly the parameters values are determined for a number of gauged catchments. Then a relationship between the model parameters and physical descriptors of those gauged catchments is derived. This relationship can use simple (e.g. multivariate regression, Sefton and Horwarth, 1998) or more sophisticated techniques (such as kriging or clustering, Vandewiele and Elias, 1995) to find similarities among the catchments.

An alternative approach to regionalisation is to assume that areas of a catchment with the same physical characteristics have similar hydrological response. Each homogeneous unit is calibrated to build a library of parameters for all units that can then be used in ungauged catchments. This type of approach is suited to semi-distributed models that use the principle of hydrological response units or to 
fully distributed models. Dunn and Lilly (2001) managed to determine parameters of the distributed DIY model according to a soil hydrological classification for two catchments in Scotland but failed to adequately calibrate the fast response. Beldring et al. (2003) calibrated a distributed version of the HBV model in 141 catchments in Norway and estimated the model parameter values for 5 land use classes. They successfully used this library of parameter values in 43 independent catchments.

Unlike many other studies where the objective has been to relate the parameters of existing models to catchment descriptors, the objective of this study is to tackle the problem in reverse. A conceptual, continuous, daily, catchment-scale rainfall-runoff model has been developed to solely utilise nationally available data with the ultimate purpose of being applied in ungauged catchments throughout the United Kingdom using the latter homogenous unit regionalisation approach. This paper presents the development and validation of the Catchment Resources and Soil Hydrology (CRASH) model, which has been based on two underpinning principals:

- Firstly, that the transformation of rainfall into simulated river discharge can be parameterised using pre-existing nationally available datasets of soil, land use and weather; and

- Secondly, that the spatial variability in soil properties and landuse is important to the hydrological response of a catchment and should be incorporated into the catchment representation.

\section{Model description}

The Hydrology of Soil Type (HOST) system (Boorman et al., 1995) has been used to classify the soils of each catchment according to their hydrological behaviour. HOST is a conceptual representation of the hydrological processes in the soil zone. All soil types (soil series) in the United Kingdom have been grouped into one of the 29 hydrological response models (or HOST classes) based on soil attributes and the dominant pathways of water movement through the soil and substrate. Allocation to a HOST class is by a hierarchical classification:

1. Soils are first allocated to one of three physical settings: 
- $\quad$ soils which overlie a permeable substrate, in which a ground water table usually exists at a depth greater than $2 \mathrm{~m}$;

- $\quad$ soils which overlie a permeable substrate, but there is a shallow water table generally within $2 \mathrm{~m}$, either in the soil or substrate;

- there is no significant groundwater or aquifer but usually a (shallow) impermeable substrate impedes vertical movement of water.

2. Each physical setting is subdivided into response models (of which there are 11 in total), which describe flow mechanisms, and which identify groups of soils that are expected to respond in the same way to rainfall.

3. Finally, there are sub-divisions of some response models according to the rate of response and the water storage within the soil profile.

The classification uses data on soil hydrogeology (parent material), depth to aquifer or ground water, presence of a peaty topsoil, depth to slowly permeable layer, depth to gleyed (or seasonally waterlogged) layer, and integrated air capacity (equivalent to drainable porosity). Multiple regressions were performed for many catchment throughout the United Kingdom, between the proportion of each hydrological response model in each catchment and the catchment's Base Flow Index (BFI) and Standard Percentage Runoff (SPR) based on river gauging data, to produce calibrated values of Base Flow Index (BFI) and Standard Percentage Runoff (SPR) for each HOST class. BFI is the long-term average proportion of flow that comes from stored sources and SPR is the percentage runoff derived from event data, adjusted to standard rainfall and catchment moisture conditions (Boorman et al., 1995).

The catchment in CRASH is composed of four types of objects: the response units (or primary object, where the model is applied), and the sub-catchments, rivers and reservoirs which are routing objects (Figure 1). The response units are defined within each sub-catchments as cells with homogeneous hydrological behaviour (Figure 1b) based upon a unique combination of soil type and land use. Similar response units in a sub-catchment are grouped together for computational efficiency. 
The model requires several types of input data: the spatial distribution of soil and land use data for the definition and parameterization of the response units; daily evapotranspiration and hourly precipitation data; catchment physical properties or descriptors for the parameterisation of the unit hydrograph at the sub-catchment scale; and river and reservoir characteristics for the flow routing.

\subsection{Response unit}

Results from response units of similar soil hydrological behaviour (or HOST class) are grouped together so that the unknown parameters are calibrated for each HOST class. The following operations are applied to the response unit:

\subsubsection{Soil water balance model}

A soil water balance using existing soil series data (horizon thickness, water contents at a range of suctions, saturated hydraulic conductivity) computes the movement of water through each soil horizon to the groundwater store, and allows temporary perched water tables within the soil profile.

The variation in mass balance of layer $i$ is expressed as:

$$
\Delta \theta_{i}=\frac{\left(D_{i-1}-D_{i}-A E T_{i}-I F_{i}\right) \Delta T}{\text { Area }^{*} \Delta z_{i}}
$$

where $\theta_{i}$ is the volumetric water content $\left(\mathrm{m}^{3} / \mathrm{m}^{3}\right), D$ the drainage $\left(\mathrm{m}^{3} / \mathrm{s}\right), A E T$ the actual crop evapotranspiration from layer $i\left(\mathrm{~m}^{3} / \mathrm{s}\right), I F$ the interflow $\left(\mathrm{m}^{3} / \mathrm{s}\right), \Delta T$ the time step $(1$ day $=86400 \mathrm{~s})$, Area the area of the HRU $\left(\mathrm{m}^{2}\right)$ and $\Delta z_{i}$ the thickness of layer $i(\mathrm{~m})$.

For the top and bottom horizons, Equation 1 becomes respectively:

$$
\begin{aligned}
& \Delta \theta_{1}=\frac{\left(I-D_{1}-A E T_{1}-I F_{1}\right) \Delta T}{\text { Area }^{*} \Delta z_{i}} \\
& \Delta \theta_{n}=\frac{\left(D_{n-1}-\operatorname{Re}-A E T_{n}-I F_{n}\right) \Delta T}{\text { Area }^{*} \Delta z_{n}}
\end{aligned}
$$

where $I$ is the infiltration $\left(\mathrm{m}^{3} / \mathrm{s}\right)$, Re the recharge to the groundwater store $\left(\mathrm{m}^{3} / \mathrm{s}\right)$ and $n$ the index of the bottom layer. 


\section{Drainage and recharge}

Drainage occurs only from horizons where the water content is above field capacity (defined at $5 \mathrm{kPa}$, Evans et al., 1999). In that case, the water movement from the layer $i$ to layer $i+1$ is derived using:

$$
D_{i}=\operatorname{Min}\left(K_{i}^{s a t} * \operatorname{Area}, K_{i+1}^{s a t} * \operatorname{Area}, \frac{\theta_{i}-\theta_{i}^{F C}}{\Delta T} * \operatorname{Area}^{*} * \Delta z_{i}, \frac{\theta_{i+1}^{\text {Sat }}-\theta_{i+1}}{\Delta T} \text { Area } * \Delta z_{i}\right)
$$

where $K^{\text {sat }}$ is the saturated hydraulic conductivity $(\mathrm{m} / \mathrm{s}), \theta^{s a t}$ and $\theta^{F C}$ are the volumetric water content at saturation and at field capacity $\left(\mathrm{m}^{3} / \mathrm{m}^{3}\right)$, respectively.

In a similar way, recharge to the groundwater store (3) occurs if the water content of the bottom horizon is above field capacity:

$$
\operatorname{Re}=\operatorname{Min}\left(K_{n}^{S a t} * \operatorname{Area}, L B K * \text { Area, } \frac{\theta_{n}-\theta_{n}^{F C}}{\Delta T} * \operatorname{Area} * \Delta z_{i}\right)
$$

$L B K$ is the lower boundary hydraulic conductivity $(\mathrm{m} / \mathrm{s})$. It parameterises the parent material and values were proposed for each HOST class by Evans et al. (1999).

\subsubsection{River flow}

The simulated river flow is composed of the contributions of interflow from the soil water store, base flow from the groundwater store and surface runoff (infiltration excess and saturation excess) from each response unit.

\section{Interflow and base flow}

The interflow ( $I F$ in $\left.\mathrm{m}^{3} / \mathrm{s}\right)$ and base flow $\left(B F\right.$ in $\left.\mathrm{m}^{3} / \mathrm{s}\right)$ are proportional to the water contents within each horizon and the groundwater store, respectively:

$$
I F=\sum_{i} I F_{i}
$$

where: 


$$
\begin{aligned}
& I F_{i}=\operatorname{Max}\left\{\left(\theta_{i}-\theta_{i}^{F C}\right) * \text { Area }^{*} \Delta z_{i} * I F K ; 0.0\right\} \\
& B F=B F K^{*} G W S C^{2}
\end{aligned}
$$

where $I F K$ and $B F K$ are the interflow and base flow coefficients in $\mathrm{s}^{-1}$ and $\mathrm{m}^{-3} \mathrm{~s}^{-1}$, respectively. GWSC is the groundwater store content $\left(\mathrm{m}^{3}\right) . I F K$ represents the lateral hydraulic conductivity of the soil.

$I F K$ is calibrated due to the difference of scale between the catchment scale application of this parameter in CRASH and the plot scale lateral hydraulic conductivities measurements available for each soil type. The parameter $B F K$ is also derived by calibration.

The groundwater store content is initialised in accordance with Hollis and Brown (1996):

$$
G W S C_{0}=0.1 * B F I * S A A R_{4170} * \frac{\text { Area }}{1000}
$$

where $S A A R_{4170}$ is the standard average annual rainfall for the period 1941-70 (mm) and $B F I$ the dimensionless base flow index.

The groundwater store content fluctuates according to the variations in recharge $R e$ and discharge (base flow- $B F$ in $\left.\mathrm{m}^{3} / \mathrm{s}\right)$ :

$$
G W S C_{t}=G W S C_{t-1}+\Delta T *(R e-B F)
$$

\section{Surface runoff}

Surface runoff $R u\left(\mathrm{~m}^{3} / \mathrm{s}\right)$ from each soil type can be either saturation excess flow (if the upper horizon is saturated) or Hortonian flow, if the rainfall intensity exceeds the saturated hydraulic conductivity of the upper horizon. The different cases are summarised below:

Case 1 saturation-excess overland flow $\theta_{1}=\theta_{1}^{\text {sat }}$ :

$$
\begin{aligned}
& I=D_{1} \\
& R u=R * \text { Area }-I
\end{aligned}
$$

Case $2 \theta_{1}<\theta_{1}^{\text {sat }}$ :

Case2.1: $\mathrm{R}<K_{1}^{\text {Sat }}$ 


$$
\begin{aligned}
& I=R * \text { Area } \\
& \mathrm{Ru}=0
\end{aligned}
$$

Case2.2: Hortonian overland flow $\mathrm{R}>K_{1}^{\text {Sat }}$

$$
R u=R * \text { Area }-I
$$

where $R$ is the hourly rainfall in $\mathrm{m} / \mathrm{s}$.

For the calculation of Hortonian flow in Case 2.2, infiltration is computed with the Philip's equation (Philip, 1957), which requires a finer, hourly, resolution of temporal rain data to determine the time period when the rainfall intensity is greater than the saturated hydraulic conductivity of the topsoil. Hourly data can be provided from existing datasets or disaggregated from daily data (e.g. Cowperwait et al., 1996; Kottegoda et al., 2003). Using Philip (1957), the infiltration after ponding $I_{a p}\left(\mathrm{~m}^{3} / \mathrm{s}\right)$ for the one directional Richard's equation for a homogeneous medium can be expressed as:

$$
I_{a p}=\text { Area }^{*} \sum_{j} \phi_{j} T_{a p} \frac{j}{2}
$$

where $T_{a p}$ is the time after ponding (s) and $j$ an index starting from $1 . \phi_{j}$ are coefficients where $\phi_{l}$ is the sorptivity $S$ and $\phi_{2}$ - noted $A$ in the rest of the text - is related to the saturated hydraulic conductivity of the soil.

If equation (13) is limited to its first two terms (Chong, 1983), the total infiltration after time $T$ (s) becomes:

$$
I * T=\text { Area }^{*}\left\{R * T_{p}+A\left(T-T_{p}\right)+S\left[\sqrt{T-\frac{S^{2}}{4 A\left(\frac{R^{2}}{A}-R\right)}}-\sqrt{T_{p}-\frac{S^{2}}{4 A\left(\frac{R^{2}}{A}-R\right)}}\right]\right\}
$$

with time to ponding $T_{p}$ (s) (Kutilek, 1980):

$$
T_{p}=S^{2} \frac{1-\frac{A}{2 R}}{2 R^{2}\left(1-\frac{A}{R}\right)^{2}}
$$


and the sorptivity $S=B \sqrt{\theta_{1}^{\text {Sat }}-\theta_{1}^{I n i}}$

with $\theta^{\text {ini }}$ the initial volumetric water content $\left(\mathrm{m}^{3} / \mathrm{m}^{3}\right)$.

The calculation of the parameter $B$ in the equation (16) is achieved in conjunction with the HOST classification. In HOST, the response runoff $R R u\left(\mathrm{~m}^{3} / \mathrm{s}\right)$, defined as the volume of fast flow during a period of $5 *$ LAG (where LAG is the time delay [d] between the centroid of rainfall and the centroid of flow peaks), for a soil at field capacity is expressed as a function of the standard percentage runoff, SPR (\%) (Boorman et al., 1995):

$$
R R u=S P R * R * \text { Area }
$$

In CRASH, $R R u$ is the sum of the surface runoff and the interflow. But in the case of a soil profile initially at field capacity, the interflow during a $5 *$ LAG period is exclusively a function of the infiltration and of $I F K$. Similarly, the surface runoff depends only on the infiltration and on the precipitation. Consequently, the only unknown in equation (17) when replacing the response runoff $R R u$ by the interflow and the surface runoff is the infiltration $I$. It is therefore possible to relate the two parameters A and B from equations (14), (15) and (16) and to conserve only one for calibration (parameter A). In total the model requires 3 parameters (A, IFK and BFK) to be calibrated for each HOST class to represent the runoff, interflow and base flow responses, respectively.

\section{Surface Depression}

The early stages of runoff generation will not necessarily lead to increased river flow due to surface storage within depressions in the landscape. The amount of water captured depends mainly on the land use and slope, although it can also be influenced by tillage, vegetation and soil type in agricultural land. Several modelling studies have presented values of the depression storage for different conditions, which can be as large as $20 \mathrm{~mm}$, but in most cases are much lower. For example, Hicks (1944) suggested values of 5.1, 3.8 and $2.5 \mathrm{~mm}$ for sand, loam and clays soils in urban areas. Zobeck and Onstad (1987) reported values of random roughness for agricultural lands after harrowing and rotary tillage below $20 \mathrm{~mm}$, which gives a depression storage of less than $3 \mathrm{~mm}$ on a zero slope. Cremers et 
al. (1996) listed random roughness for various crops and tillage directions which were, with the exception of potatoes and fallow with tillage perpendicular to the slope, below $18 \mathrm{~mm}$. However, despite the above studies there is insufficient nationally-available data (especially land management data) to parameterise depression storage for the full range of soil-crop/landuse combinations so, as a necessary simplification, the depression storage in CRASH has been set to $4.0 \mathrm{~mm}$. The water filling up the depression storage is extracted from the surface runoff component, exclusively, and is available for infiltration in the next time step.

\subsubsection{Actual Evapotranspiration}

Actual evapotranspiration is computed according to Allen et al (1998) as the potential evapotranspiration PET (m/s) corrected by a crop coefficient and a water stress coefficient.

$$
A E T=P E T * C_{c} * C_{s} * \text { Area }
$$

$C_{c}$ is a crop coefficient to relate the transpiration from a crop to that of a reference crop (grass), and varies with crop type and time within the cropping year. $C_{s}$ is a water stress coefficient which allows for the reduced ability of the crop to extract water at high and low soil moisture contents (Figure 3).

The water uptake by roots is calculated following the model of Jarvis (1989) where the soil water extracted from each soil horizon $S W E\left(\mathrm{~m}^{3} / \mathrm{s}\right)$ is expressed as:

$$
S W E_{i}=\frac{A E T}{\Delta z_{i}} \frac{P_{i} \alpha_{i}}{\bar{\alpha}}
$$

$P_{i}$ and $\alpha_{i}$ are the proportion of root length density within a layer and a reduction factor due to water shortage, respectively. They are functions of the mid-point depth of the layer below the soil surface for $P_{i}$ and of the water content within the layer for $\alpha_{i} . \bar{\alpha}$ is the average value of $\alpha_{i}$.

Finally, the development of the root zone depth $R D(\mathrm{~m})$ is simulated following the empirical equation of Borg and Grimes (1986): 


$$
R D=R D^{\max } *\left[0.5+0.5 * \sin \left(3.03 * \frac{T F P}{D R G}-1.47\right)\right]
$$

where $R D^{\max }$ is the maximum root zone depth (m), TFP the time from planting (d) and $D R G$ the duration of root growth (d).

\subsection{Routing Objects}

\subsubsection{Sub-catchment}

There are various methods to transfer the surface runoff and interflow towards the catchment or subcatchments outlet. The unit hydrograph method has been selected, although the choice of method does not have a major impact on the shape of the hydrograph (Todini, 1996). Several studies have reported equations to derive catchment parameters specific to the UK (e.g. NERC, 1975; Institute of Hydrology, 1985; Marshall, 2000), of which Institute of Hydrology (1985) has been selected for its simplicity. The unit hydrograph time-to-peak Ttp is estimated as:

$$
T t p(0)=283 * S 1085^{-0.33} * S A A R_{4170}{ }^{-0.54} * M S L^{0.23} *\left(1+U R B A N_{F S R}\right)^{-2.2}
$$

where $S 1085$ the $10-85 \%$ channel slope $(\mathrm{m} / \mathrm{km}), M S L$ the main stream length $(\mathrm{km})$ and $U R B A N_{F S R}$ the urbanisation index.

\subsubsection{River routing}

The Muskingum-Cunge (Cunge, 1969) technique is used to route the upstream hydrograph through the main channel. This non-linear method requires a representative channel cross section, the main channel length, the Manning roughness coefficient and the channel bed slope.

\subsubsection{Reservoir routing}

The level pool routing technique developed by Chow et al. (1988) can be activated to account for reservoirs in the catchment. The continuity equation in the reservoir is expressed as:

$$
\frac{d L}{d T}=\frac{\operatorname{In}(T)-Q(L)}{R \operatorname{Area}(L)}
$$


where $L$ is the reservoir level (m), In is the inflow $\left(\mathrm{m}^{3} / \mathrm{d}\right), Q$ the reservoir outflow $\left(\mathrm{m}^{3} / \mathrm{s}\right)$ and RArea the reservoir area $\left(\mathrm{m}^{2}\right)$.

A third order Runge-Kutta scheme is performed to solve Equation (22) (Chow et al. (1988). The arealevel relationship RArea(L) depends on the topography of the shore. This relationship is assumed to be linear as it only fails in exceptional cases (Reed, 1999).

\section{Case studies}

Three study catchments were selected which represent the three physical settings within the HOST classification. The spatial distribution of soil map units and constituent soil series were taken from the national soil map of England and Wales (Ragg et al., 1984). Figure 4 shows the dominant HOST class in each soil map unit, although all soil types (and HOST classes) within each soil map unit are simulated. The distribution of land use classes (aggregate of crops/land uses) was taken from the Centre for Ecology and Hydrology's Land Cover Map of Great Britain 1990, with official 1988 agricultural statistics used to define the proportion of each crop in the arable land areas. It was assumed that a crop/land use was spread uniformly among the soil types within an area composed of a soil unit and a land use class.

\subsection{Amesbury catchment}

The Amesbury catchment, in the south of England, covers an area of $320 \mathrm{~km}^{2}$ with an elevation between 54 to $303 \mathrm{~m}$ above sea level (asl). Average annual precipitation is $735 \mathrm{~mm}$ and the annual average river flow at the catchment outlet is $300 \mathrm{~mm}$. The main land use is grassland, with arable crops found in the northern part of the catchment. About two thirds of the catchment is covered by soils of HOST class 1, which overlie a permeable substrate (in this case chalk) in which groundwater usually exists at a depth of more than $2 \mathrm{~m}$. HOST class 16, in which there is no significant underlying aquifer and surface runoff is likely, covers much of the remaining catchment. 


\subsection{Gwills catchment}

The Gwills catchment, in the south west of England, is the smallest $\left(42 \mathrm{~km}^{2}\right)$ and wettest (average annual rainfall and river flow of $970 \mathrm{~mm}$ and $540 \mathrm{~mm}$, respectively) of the three study catchments. Elevation ranges from 10 to $217 \mathrm{~m}$ asl. Grassland is the main land use with subsidiary areas of arable. The catchment is dominated by soils of HOST class 17, which has similar properties to those presented above for class 16. HOST class 9 belong to the final physical setting, having an aquifer and shallow water table within the first $2 \mathrm{~m}$ of the profile

\subsection{Avon catchment}

The Avon catchment contains a reservoir which receives inflows from an area of $12 \mathrm{~km}^{2}$ of the 100 $\mathrm{km}^{2}$ of the entire catchment. Elevation ranges from 30 to $225 \mathrm{~m}$ asl. The catchment is mainly arable, with grassland found where the topography is less favourable to agriculture. The annual average rainfall and river flow are $650 \mathrm{~mm}$ and $180 \mathrm{~mm}$, respectively. Nearly $90 \%$ of the area is characterised by soils developed in impermeable clays or mudstones, dominated by HOST classes 23 and 25 .

\section{Calibration}

CRASH has been calibrated for the three study areas using Monte Carlo modelling. Monte Carlo sampling has been used to generate 5000 parameter sets for which the distributions of the parameters were assumed to be uniform in their range of variation. The best parameter set was selected as the one giving the best fit between observed and simulated flows according to a multi-objective function.

Yu and Yang (2000) demonstrated the advantages of a multi-objective function for the calibration of a hydrological model and suggested a fuzzy multi-objective function (FMOF) which accounts for all the parts of the hydrograph:

$$
F M O F=1-\min _{i} \mu_{i}\left(M P E_{i}\right)
$$


where $M P E_{i}$ is the mean absolute percentage error for the $i$ th flow stage (equation 24) and $\mu_{i}\left(M P E_{i}\right)$ is the membership function of the MPE (Figure 5) The flow duration curve is divided into a number of stages, at $0,5,10,20,30,40,50,60,70,80,90$ and $100^{\text {th }}$ percentiles.

$$
M P E_{i}=\frac{1}{N_{i}} \sum_{j}\left|\frac{O b s_{j}-\operatorname{Sim}_{j}}{O b s_{j}}\right| * 100 \%
$$

The calibration periods for the catchments were 1980-1984 (Amesbury) and 1979-1984 (Gwills and Avon). Table 1 gives the results for the FMOF and the Nash-Sutcliffe $\left(\mathrm{R}^{2}\right)$ efficiency index. The FMOF gives an indication on the goodness of fit for the stage of the flow duration curve where the simulation is the most different from observations. The optimal value is 0.0 which means that there is no difference between the two duration curves and a FMOF of 1.0 means that the mean absolute percentage error is $100 \%$ in all parts of the flow duration curve. On the other hand, $\mathrm{R}^{2}$ is based on the time series and accounts for the entire hydrograph. It indicates the overall goodness of fit of the simulation. Sefton and Howarth (1998) proposed that $\mathrm{R}^{2}$ be adopted as the criteria to reject the calibration of a model, and suggested a minimum value of 0.5 as the threshold for acceptance. CRASH fulfils this requirement and can be considered as sufficiently calibrated.

The time series and flow duration curves for the three simulations are compared to observations in Figures 6 and 7. The calibrated parameter values for the main HOST classes, which cover $80 \%$ or more of each catchment, are given in Table 2. For the two physical settings with permeable substrates (aquifers) in which the base flow contribution is high, the base flow parameter are lower for those HOST classes with deep (> $2 \mathrm{~m}$ ) groundwater (classes 1, 2 and 6) compared to shallow $(<2 \mathrm{~m})$ groundwater (classes 8 and 9). For the former physical setting, the lowest base flow parameter (and therefore the slowest recession) is for HOST class 1 which is consistent with the low seasonal variability in base flow in chalk catchments in the UK. For the final physical setting in which there is a shallow impermeable substrate (classes 16, 17, 23 and 25), there is an increase in the surface runoff parameter with increasing soil waterlogging.

\section{Validation}


Whether a theory can or can not be validated has been extensively discussed, but it is now generally agreed that a theory, and thus a model, can only be invalidated. The criteria chosen to be able to reject the model and its calibration in one or more of the catchments is the same as that used during the calibration exercise (Nash-Sutcliffe efficiency index $\mathrm{R}^{2}<0.5$ ), which CRASH exceeds in all catchments (Table 3) ..

Having rejected the invalidation test, it is possible to further evaluate the matches between simulated and observed flows through numerical (Table 3) and graphical (Figures 8 and 9) comparisons. Table 3 summarises the results for FMOF, Nash-Sutcliffe efficiency index $\left(\mathrm{R}^{2}\right)$ and percent bias (PBIAS). The PBIAS is a measure of the bias of the model (equation 25), with a tendency to overestimate indicated by a positive value and a tendency to underestimate by a negative value.

$$
P B I A S=\frac{\sum_{j}\left(\operatorname{Sim}_{j}-O b s_{j}\right)}{\sum_{j} O b s_{j}} * 100 \%
$$

CRASH tends to overestimate the river flows for the Amesbury catchment during the validation period $($ PBIAS $=16.3 \%)$. The overestimation is mainly located in the low flows and explains the change of FMOF from 0.32 in the calibration period to 0.52 in the validation period. However, the overall behaviour of the model is very acceptable and has even slightly improved $\left(\mathrm{R}^{2}\right.$ has increased from 0.83 to 0.86 ) because, although the relative difference between observations and simulation has increased in the low flows, the absolute difference on the whole hydrograph has decreased.

Although CRASH has a tendency to slightly overestimate the river flow in the Gwills catchment, flows are underestimated between the $60^{\text {th }}$ and $95^{\text {th }}$ percentiles in the flow duration curve which are mainly associated with recession flows. This suggests that recharge to the ground water store is slightly underestimated. The decrease in the efficiency index (from 0.64 during calibration to 0.54 during validation) is not solely the consequence of the underestimation of the recession flows, but also of the timing of the high flows, although the flow duration curves from the observations and the simulation match well.

There is good agreement between the two flow duration curves in the Avon catchment, with the FMOF showing that there is no stage where the simulated flow duration curve is significantly different from 
the observed one, the PBIAS is small and the $\mathrm{R}^{2}$ has remained at around 0.55 . The main soils of the Avon catchment are slowly permeable, seasonally wet soils from which runoff occurs frequently. Differences in the estimation of the high flow events have an effect on the value of $\mathrm{R}^{2}$ as CRASH tends to underestimate these high flows in this catchment.

\section{Discussion and conclusion}

The conceptual, continuous, daily, catchment-scale rainfall-runoff CRASH model has been developed to solely utilise nationally available datasets, with the ultimate purpose of being applied in ungauged catchments throughout the United Kingdom. CRASH was tested in three diverse catchments, which were chosen to contain soils from the three main physical settings of soil hydrology within the HOST soil hydrological classification. CRASH was successful in simulating both daily time series and flow duration curves in each catchment, although it appears to have a slight tendency to overestimate river discharge.

Unlike many daily timestep, conceptual models (e.g. SWAT - Arnold et al., 1999; DIY- Dunn and Lilly, 2001), CRASH is able to separate the processes of infiltration-excess runoff generation from saturation-excess runoff by solution of the Philips infiltration equation using hourly rainfall data. Although infiltration-excess is not the dominant mechanism of runoff generation in the UK and much of north-western Europe, it can be important on bare soils and where inappropriate timing of land management operations, such as ploughing or harvesting, causes compaction and structural damage, leading to a reduction in soil water storage and infiltration capacity, and an increase in runoff (Holman et al. 2003). By combining an explicit separation and physically-based simulation of saturation and infiltration-excess runoff with full representation of spatial variability in landuses and soils, a complete description of each soil's profile (including the hydraulic conductivity and soil water release characteristics of each soil layer) and a surface depression storage term, CRASH provides the basis for significant improvement in the process representation of land management-induced changes in hydrological response within semi-distributed conceptual models.

The capacitance approach used by CRASH for redistribution of soil water within the soil profile has been integrated with soil survey data at horizon, soil taxonomic and spatial soil map units levels, 
morphological characteristics describing soil hydrological states (e.g. gleying) and soil physical properties to simulate the vertical and lateral pathways of water movement through the soil. The successful cross-scale linkage between the water movement through the soil profile and the catchmentscale hydrological response has been achieved using an existing national hydrologically-relevant dataset: the Hydrology of Soil Types (HOST) classification. The HOST classification is capable of predicting river flow levels of ungauged catchments throughout the United Kingdom $\left(\mathrm{r}^{2}=0.79\right.$, standard error of estimate of 0.089 in the case of Base Flow Index) by linking catchment-scale hydrological indices (Base Flow Index and Standard Percentage Runoff) with national soil map data,. The scale effects between plot and catchments, which can be explained by the configuration of hydrological response units and their connection to the flow network system (Cerdan et al., 2004), are implicit within the calibration of the hydrological response of the soil landscape-based HOST classes.

The robust relationships between HOST classes and SPR and BFI have enabled the use of HOST in flood estimation (e.g. Reed, 1999) and low flow estimation (Gustard et al., 1992; Young et al., 2000) approaches to predict individual events and flow duration curves, but CRASH represents the first application to successfully parameterise all parts of the time series hydrograph. The next developmental stage with CRASH will be to regionalise the parameter sets in order to assess whether it is possible to obtain a single set for each HOST class. Kuczera (1997) suggested that the regionalisation of the calibration brings more constraints and that these constraints can actually improve the efficiency of the parameterisation. Early results (Maréchal and Holman, 2002) show promise for a HOST-based regionalization approach, which is supported by Dunn and Lilly (2001)

The information held in data used for the calibration of hydrological models e.g. river flow data is generally insufficient to determine a unique set of model parameters (Beven and Freer, 2001). Other sources and types of information can help to reduce the uncertainty on model parameters. Siebert and McDonnell (2002) made the distinction between quantitative data that they called hard data, and qualitative or soft data. Hard data are measurements of the states of water bodies, and can be represented in models as internal state variables. Soft data represent the qualitative knowledge of the hydrological processes in the catchment. The use of soft data has not yet had as clear a success as hard data, but Seibert and McDonnell (2002) claim that their incorporation into the calibration procedure is a valuable tool to better link the modelling exercise to our knowledge of the "real" world and which, through the extra knowledge introduced into the model, provides extra confidence into its behaviour. 
The ability to incorporate such soft data within regionalization studies has been limited by the difficulty of producing concise, easily understood explanations of different basin behaviours (McDonnell and Woods, 2004). The hydrological cycle and principle of mass conservation as unifying concepts within hydrological sciences do not provide sufficient information on the partitioning of water among pathways, which might be aided by an agreed catchment classification scheme which describes, at is most fundamental level, fluxes, storages and response times (McDonnell and Woods, 2004). A soil hydrological classification, similar to HOST or the USDA Curve Number (SCS 1985), might form one component of such a classification scheme. The Curve Number approach relates soil hydrological group, soil condition, landuse, land management practices and antecedent soil moisture condition to catchment-scale runoff. Although similarly empirical, having been derived from a number of catchment studies in the US, the Curve Number approach has successfully informed hydrological simulations across the United States (e.g. Arnold et al. 1999) and, with calibration, in other countries (e.g. Germany- Krysanova and Becker, 2000; Belgium- Griensven and Bauwens, 2001). Although the HOST classification has been developed and calibrated in the UK, Holman and Hollis (2000) describe a methodology for deriving HOST classes across Europe based upon the same diagnostic properties, from the Soil Map of Europe (Commission of the European Community, 1985). This have been successfully applied and calibrated in Spain (Verdú Vázquez, 2004; Llanos Rodríguez 2004) and Sweden (Holman and Hollis, 2000).

One of the five directions of work within the International Association of Hydrological Sciences (IAHS) Predictions in Ungauged Basins (PUB) decadal initiative (Sivapalan et al., 2003) is to "advance the technological capability around the world to make predictions in ungauged basins, firmly based on local knowledge of the climatic and landscape controls on hydrological processes". HOST and the Curve Number are useful in catchment modelling for grouping soils by similar hydrological behaviour, providing initial quantitative values of hydrological response, and for constraining free parameter values during catchment-specific calibration (e.g. Dunn and Lilly, 2001). Such classifications of soil hydrological behaviour provide a sound and consistent framework for hydrological modelling in both gauged and ungauged catchments which should be extended to other regions to support the PUB initiative. 


\section{Acknowledgements}

This work was funded by the European Commission Framework V Programme as part of the MULINO project (EVK1-2000-22089). We gratefully acknowledge the Environment Agency for the flow data, the British Atmospheric Data Centre for providing access to the UK Meteorological Office Land Surface Observation Stations Data and to the UK Meteorological Office for the use of their data, the Centre for Ecology and Hydrology for the land cover map and the National Soil Resources Institute for the soil information. The advice of colleagues, especially John Hollis, Keith Weatherhead and Sue White, are gratefully acknowledged.

\section{References}

Abbott, M.B., Bathurst J.C., Cunge J.A., O'Connell P.E., Rasmussen J., 1986. An introduction to the European Hydrological System - Système Hydrologique Européen, "SHE", 1: history and philosophy of a physically-based distributed modelling system. J. Hydrol. 87, 45-59.

Allen, R.G., Pereira L.S., Raes D., Smith M., 1998. Crop evapotranspiration: guidelines for computing crop water requirements. FAO Irrigation and Drainage Paper 56. Food and Agriculture Organization of the United Nations. Rome.

Arnold, J.G., Srinivasan, R., Muttiah, R.S., Allen, P.M., 1999. Continental scale simulation of the hydrologic balance. J. Amer. Water Res. Assoc., 35(5), 1037-1051

Beldring, S., Engeland, K., Roald, L.A., Sælthun, N.R., Voksø, A., 2003. Estimation of parameters in a distributed precipitation-runoff model for Norway. Hydrol. and Earth Syst. Sci. 7(3): 304-316.

Beven, K., 1989. Changing ideas in hydrology - the case of physically-based models. J. Hydrol. 105, $157-172$.

Beven K, Freer J., 2001. Equifinality, data assimilation, and uncertainty estimation in mechanistic modelling of complex environmental systems using the GLUE methodology. J. Hydrol. 249 (1-4): 1129 
Boorman, D.B., Hollis J.M., Lilly A., 1995. Hydrology of soil types: a hydrologically-based classification of the soils of the United Kingdom. Institute of Hydrology report no. 126.

Borg H., Grimes, D.W., 1986. Depth development of roots with time: An empirical description. Trans. ASAE.; 29, 194-197.

Cerdan, O., Le Bissonnais, Y., Govers, G., Lecomte, V., van Oost, K., Couturier, A., King, C., Dubreuil, N., 2004. Scale effect on runoff from experimental plots to catchments in agricultural areas in Normandy. J. Hydrol. 299, 4-14.

Chong, S.K., 1983. Calculation of sorptivity from constant-rate rainfall measurement. Soil Sci. Soc. Am. J. 47, 627-630.

Chow, V.T., Maidment D.R., Mays L. W., 1988. Applied hydrology, McGraw-Hill.

Commission of the European Community, 1985: Soil Map of the European Communities 1:1,000,000.

CEC-DGVI, Luxembourg, 124pp., 7 maps.

Cowperwait, P.S.P., O’Connell P.E., Metcalfe, A.V., Mawdsley, J.A., 1996. Stochastic point process modelling of rainfall. I Regionalisation and disaggregation. J. Hydrol. 175, 47-65.

Cremers, N.H.D.T., van Dijk P.M., de Roo A.P.J., Verzandvoort M.A., 1996. Spatial and temporal variability of soil surface roughness and the application in hydrological and soil erosion modelling. Hydrol. Proc. 10, 1035-1047.

Cunge, J.A., 1969. On the subject of flood propagation method (Muskingum method). J. of Hydraul. Res., IAHR. 7(2), 205-230.

Dunn, S.M., Lilly A., 2001. Investigating the relationship between a soils classification and the spatial parameters of a conceptual catchment-scale hydrological model. J. Hydrol.; 252, 157-173.

Evans, S.P., Mayr T.R., Hollis J.M., Brown C.D., 1999. SWBCM: a soil water balance capacity model for environmental applications in the UK. Ecol. Model. 121, 17-49.

Freeze, R.A., Harlan R.L. 1969. Blueprint for a physically-based, digitally simulated, hydrologic response model. J. Hydrol. 9, 237-258. 
Griensven, A.V., Bauwens, W., 2001. Integral water quality modelling of catchments. Water Science and Technology, 43(7), 321-328.

Gustard, A., Bullock, A., Dixon, J.M., 1992. Low flow estimation in the United Kingdom. Institute of Hydrology report No. 108, Wallingford, UK.

Hicks, W.I., 1944. A method of computing urban runoff. Trans. ASAE. 109, 1217-1253.

Hollis, J.M., Brown, C.D., 1996. A catchment-scale model for pesticides in surface water. In Del Re, A.A.M., Capri, E., Evans, S.P., Trevisan, M.(eds). The environmental fate of Xenobiotics. Proceeding of the X Symposium Pesticide Chemistry, Piacenze, Italy.

Holman, I.P., Hollis, J.M. (eds.), 2001. Upscaling, Predictive Models and Catchment Water Quality: the CAMSCALE project. Final Report of EU Fourth Framework Project No. ENV4-CT97-0439

Holman, I.P., Hollis, J.M., Bramley, M.E., Thompson, T.R.E., 2003. The contribution of soil structural degradation to catchment flooding: a preliminary investigation of the 2000 floods in England and Wales. Hydrology and Earth System Sciences, 7(5), 754-765.

Institute of Hydrology, 1985. The FSR rainfall-runoff model parameter estimation equations updated. Flood studies supplementary report no. 16. Inst. of Hydrol., Wallingford..

Jakeman, A. Hornberger G., 1993. How much complexity is warranted in a rainfall-runoff model. Wat. Res. Res. 29, 2637-2649.

Jarvis, N.J., 1989. A simple empirical model for root water uptake. J. Hydrol. 107, 57-72.

Kottegoda, N.T., Natale, L., Raiteri, E., 2003. A parsimonious approach to stochastic multisite modelling and disaggregation of daily rainfall. J. Hydrol. 274, 47-61.

Krysanova, V., Becker, A., 2000. Integrated modelling of hydrological processes and nutrient dynamics at the river basin scale. Hydrobiologia, 410, 131-138.

Kuczera, G., 1997. Efficient subspace probabilistic parameter optimization for catchment models. Wat. Res. Res. 33(1), 177-185. 
Kutilek, M., 1980. Constant-rainfall infiltration. J. Hydrol. 45, 289-303.

Llanos Rodríguez, J., 2004. Application of the conceptual rainfall-runoff model CRASH in the Spanish mountainous catchment of the Aragón river. Unpubl. MSc thesis, Cranfield University, UK.

Maréchal, D., Homan I. P., 2002. A soil hydrology-based catchment water resources model.

Proceedings International Conference on Integrated Assessment and Decision Support (iEMSs2002). Lugano, Italy, June 24-27; Volume 1, 452-457.

Marshall, D.C.W., 2000. The estimation of flood response times from the digital catchment data. J. C. Instn. Wat. \& Envir. Mangt.. 14(5), 335-340.

McDonnel, J.J., Woods, R., 2004. On the need for catchment classification. J. Hydrol. 299, 2-3.

Natural Environment Research Council. 1975. Flood studies report, NERC, London, 5 vols..

Philip, J.R., 1957. The theory of infiltration: 1. the infiltration equation and its solution. Soil Sci. 83, $345-357$.

Ragg, J.M., Beard, G.R., George, H., Heaven, F.W., Hollis, J.M., Jones, R.J.A., Palmer, R.C., Reeve, M.J., Robson, J.D., Whitfield, W.A.D., 1984. Soils and their use in Midland and western England. Soil Survey of England and Wales Bulletin No. 12: Harpenden.

Reed D., 1999, Flood estimation handbook, 1: Overview. Institute of Hydrology, Wallingford, Oxford.

Sefton, C.E.M., Howarth S.M., 1998. Relationships between dynamic response characteristics and physical descriptors of catchments in England and Wales. J. Hydrol. 211, 1-16.

Seibert, J., 1999. Regionalisation of parameters of a conceptual rainfall-runoff model. Agric. For. Meteorol. 98-99, 279-293.

Seibert, J., McDonnell, J.J., 2002. On the dialog between experimentalist and modeler in catchment hydrology: Use of soft data for multicriteria model calibration. Water Resources Research. 38(11): 1241.

Sivapalan, M., Takeuchi, K., Franks, S.W., Gupta, V.K., Karambiri, H., Lakshmi, V., Liang, X., 
McDonnell, J.J., Mendiondo, E.M., O'Connell, P.E., Oki, T., Pomeroy, J.W., Schertzer, D., Uhlenbrook, S., Zehe, E., 2003. IAHS decade on Predictions in Ungauged Basins (PUB), 2003-2012: Shaping an exciting future for the hydrological sciences. Hydrological Sciences Journal-Journal des Sciences Hydrologiques. 48 (6): 857-880.

Soil Conservation Service, 1985. National engineering handbook. Section 4- Hydrology. Washington, DC.

Todini, E., 1996. The ARNO rainfall-runoff model. J. Hydrol. 175, 339-382.

Vandewiele, G.L., Elias, A., 1995. Monthly water balance of ungauged catchments obtained by geographical regionalization. J. Hydrol. 170, 277-291.

Verdú Vázquez, J., 2004. Water balance modelling of the River Meca at Huelva, Spain. Unpubl. MSc thesis, Cranfield University, UK.

Young, A.R., Gustard, A., Bullock, A., Sekulin, A.E., Croker, K.M., 2000. A River network based hydrological model for predicting natural and influenced flow statistics at ungauged sites: Micro LOW FLOWS. The Science of the Total Environment, 251/252, 293-304.

Yu, P.S., Yang T.C., 2000. Fuzzy multi-objective function for rainfall-runoff model calibration. J. Hydrol. 238, 1-14.

Zobeck, T. M., Onstad C. A., 1987. Tillage and rainfall effects on random roughness: a review. Soil \& Til. Res. 9, 1-20. 
Table 1: Statistical results - calibration period

\begin{tabular}{cccc}
\hline & Amesbury & Gwills & Avon \\
\hline FMOF & 0.32 & 0.35 & 0.22 \\
$\mathrm{R}^{2}$ & 0.83 & 0.64 & 0.54 \\
\hline
\end{tabular}


Table 2: Calibrated parameters for the main HOST classes

\begin{tabular}{ccccc}
\hline HOST class & Catchment & $\begin{array}{c}\text { Surface runoff } \\
\text { parameter }\end{array}$ & $\begin{array}{c}\text { Interflow } \\
\text { parameter }\end{array}$ & $\begin{array}{c}\text { Base flow } \\
\text { parameter }\end{array}$ \\
\hline 1 & Amesbury & 0.46 & 0.07 & $5.6 \mathrm{E}-5$ \\
2 & Avon & 0.19 & 0.12 & $6.7 \mathrm{E}-5$ \\
6 & Gwills & 0.24 & 0.19 & $6.7 \mathrm{E}-5$ \\
8 & Gwills & 0.19 & 0.15 & $1.8 \mathrm{E}-4$ \\
9 & Gwill & 0.02 & 0.24 & $1.2 \mathrm{E}-4$ \\
16 & Amesbury & 0.16 & 0.06 & $3.7 \mathrm{E}-5$ \\
17 & Gwills & 0.18 & 0.06 & $3 \mathrm{E}-4$ \\
23 & Avon & 0.37 & 0.03 & $1.4 \mathrm{E}-3$ \\
25 & Avon & 0.41 & 0.55 & $1.2 \mathrm{E}-5$ \\
\hline
\end{tabular}


Table 3: Statistical results - validation period

\begin{tabular}{cccc}
\hline & Amesbury & Gwills & Avon \\
\hline FMOF & 0.51 & 0.43 & 0.24 \\
$\mathrm{R}^{2}$ & 0.86 & 0.54 & 0.55 \\
PBIAS $(\%)$ & 16.3 & 6.5 & 8.8 \\
\hline
\end{tabular}


Figure 1: Structure of the CRASH model composed of a) Response unit, b) Subcatchment, c) Catchment, and d) the conceptual representation of the catchment

Figure 2: Example variation in the water stress coefficient $\left(\mathrm{C}_{\mathrm{s}}\right)$ according to soil water content

Figure 3: Location of the study catchments

Figure 4: HOST classes within the (top) Amesbury, (middle) Gwills and (bottom) Avon catchments

Figure 5: Membership function of the mean percentage error (MPE) used in the fuzzy multi-objective function (FMOF)

Figure 6: Observed and simulated daily streamflow for the (top) Amesbury, (middle) Gwills and (bottom) Avon catchments during the calibration periods

Figure 7: Observed and simulated flow duration curves for the (top) Amesbury, (middle) Gwills and (bottom) Avon catchments during the calibration periods

Figure 8: Observed and simulated daily streamflow for the (top) Amesbury, (middle) Gwills and (bottom) Avon catchments during the validation periods

Figure 9: Observed and simulated flow duration curves for (top) Amesbury, (middle) Gwills and (bottom) Avon catchments during the validation periods 


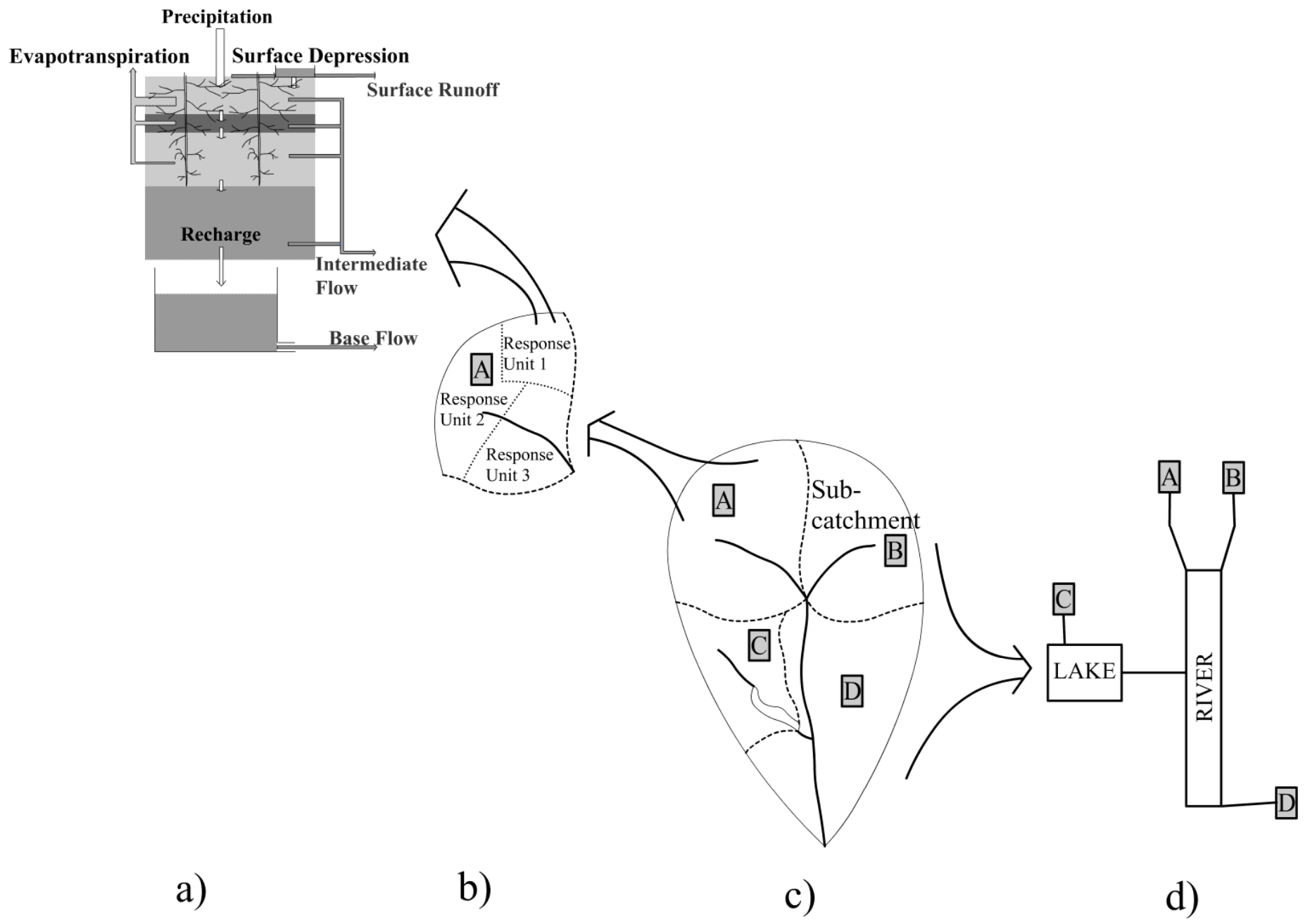

Figure 1 


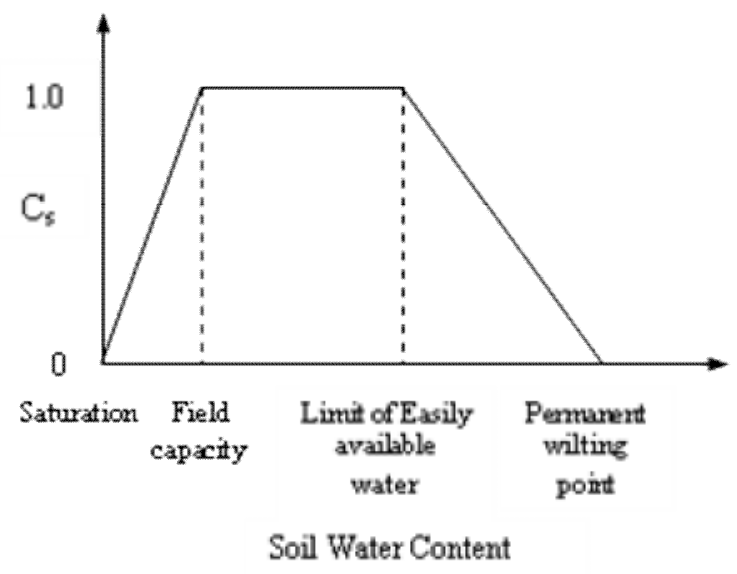

Figure 2 


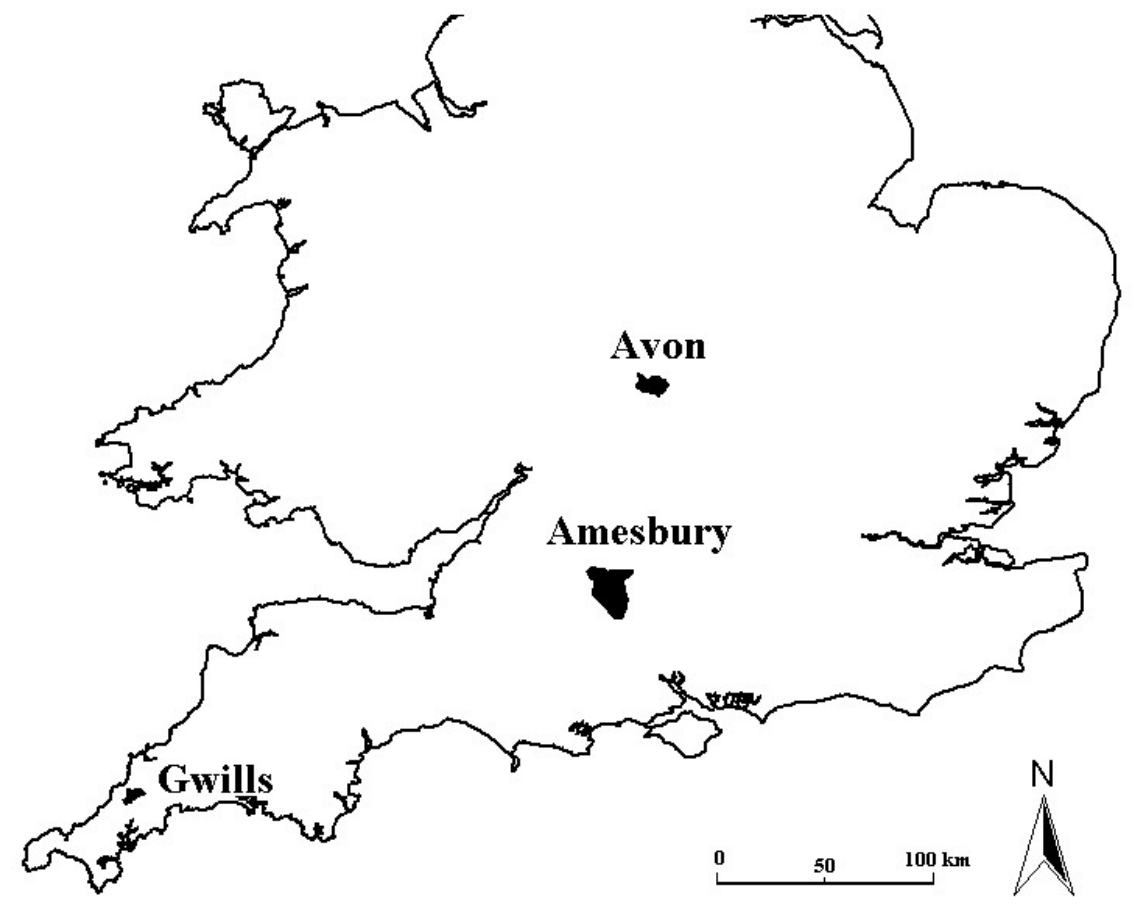

Figure 3 


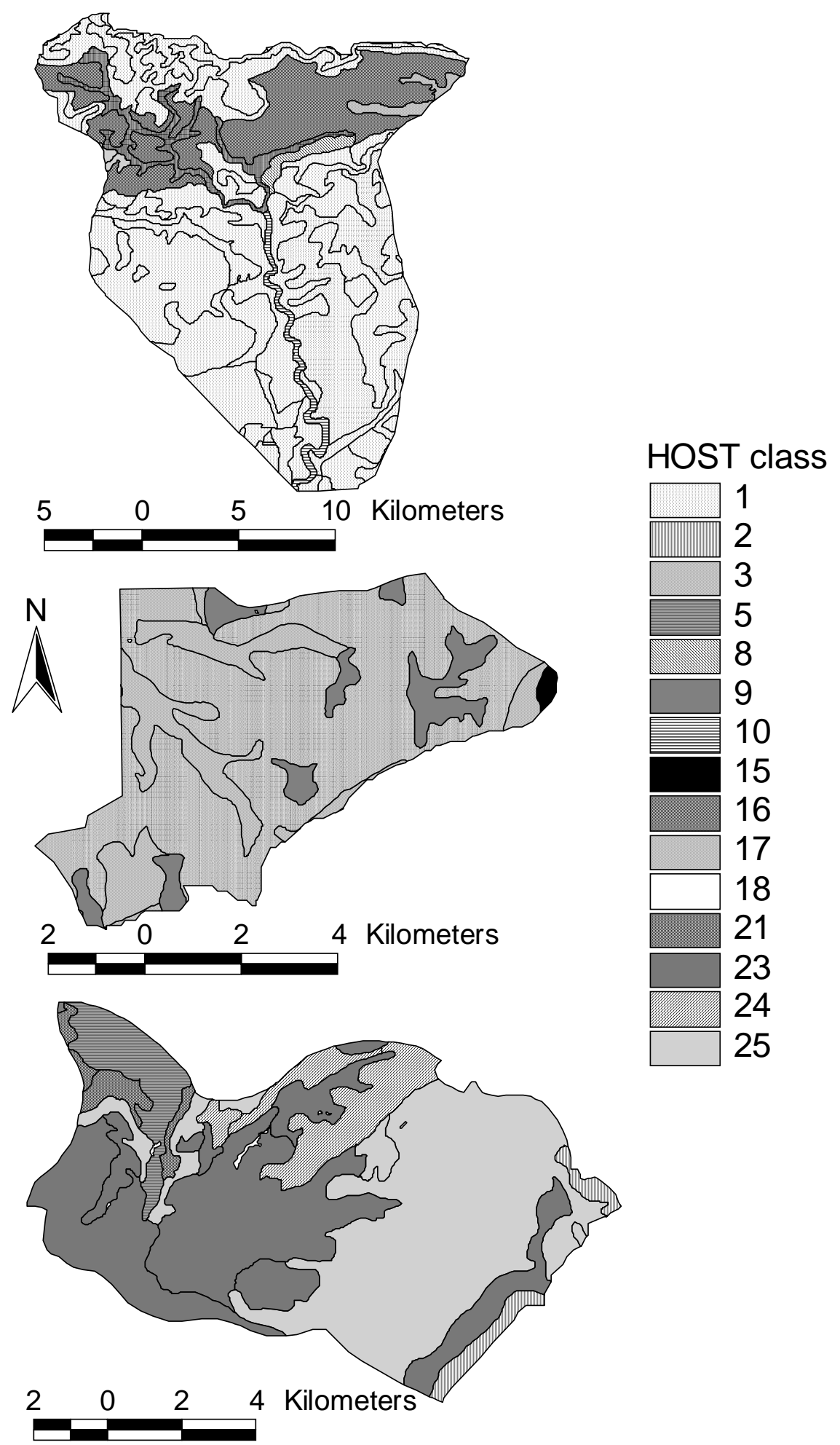

Figure 4 


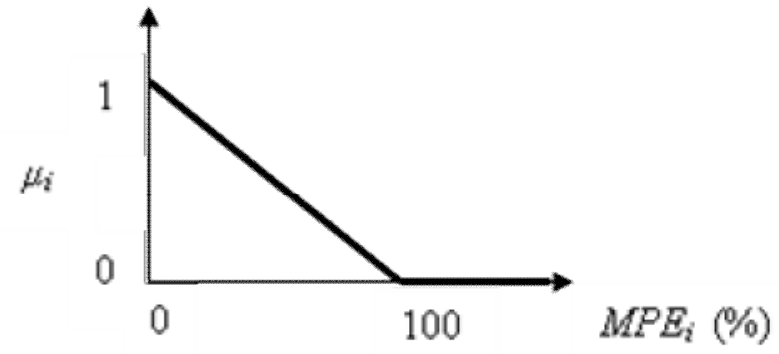

Figure 5 

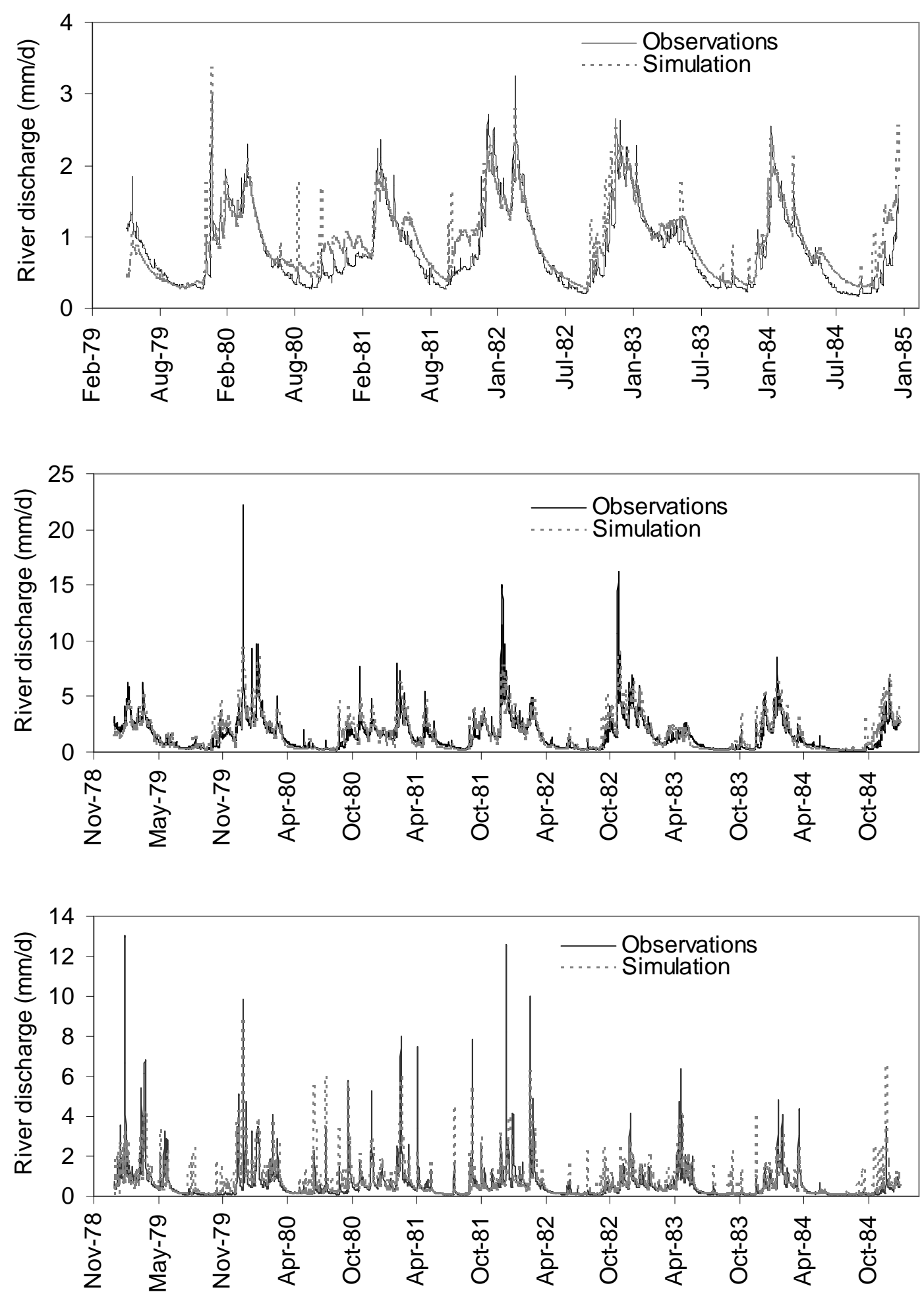

Figure 6 

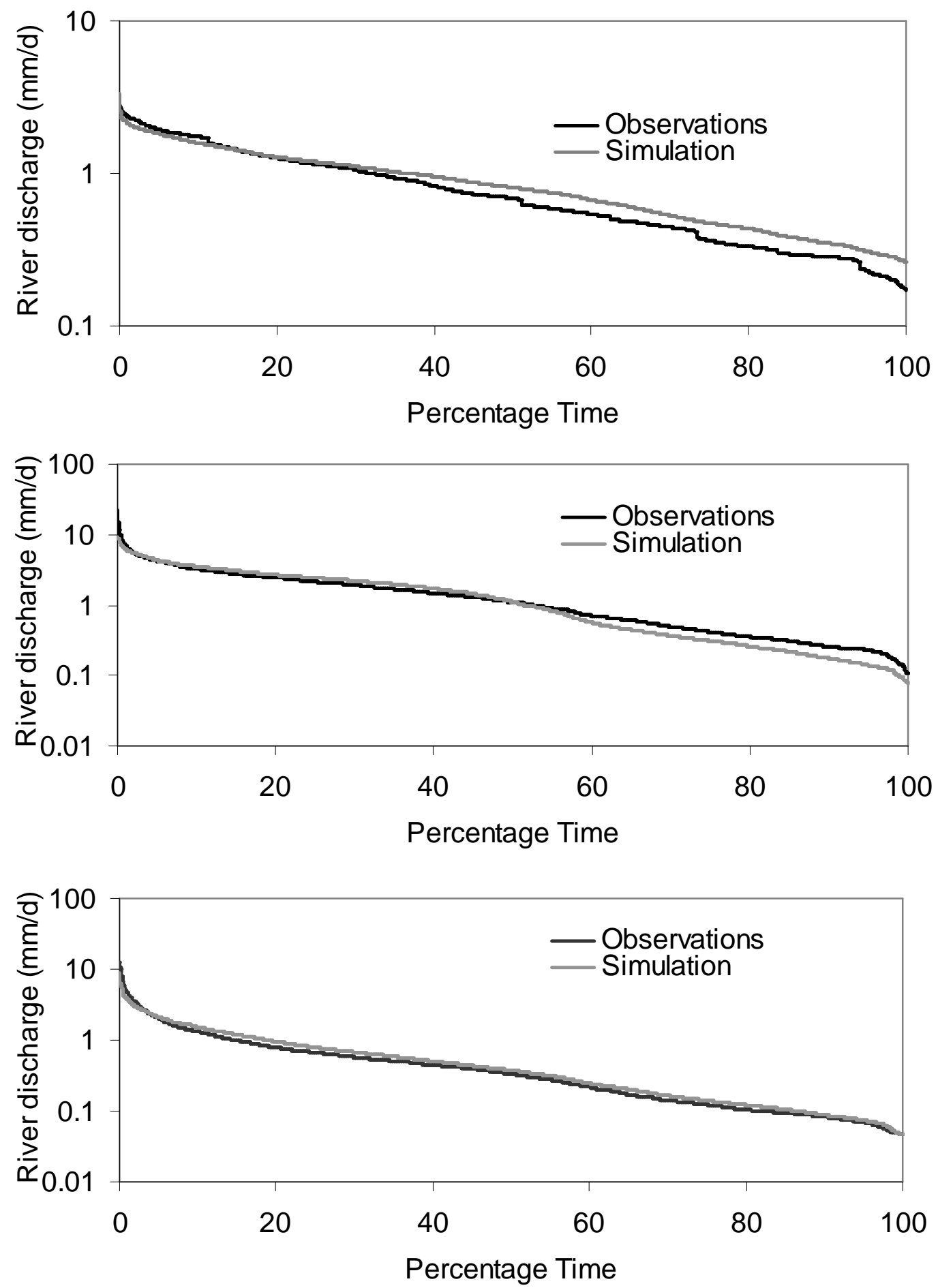

Figure 7 

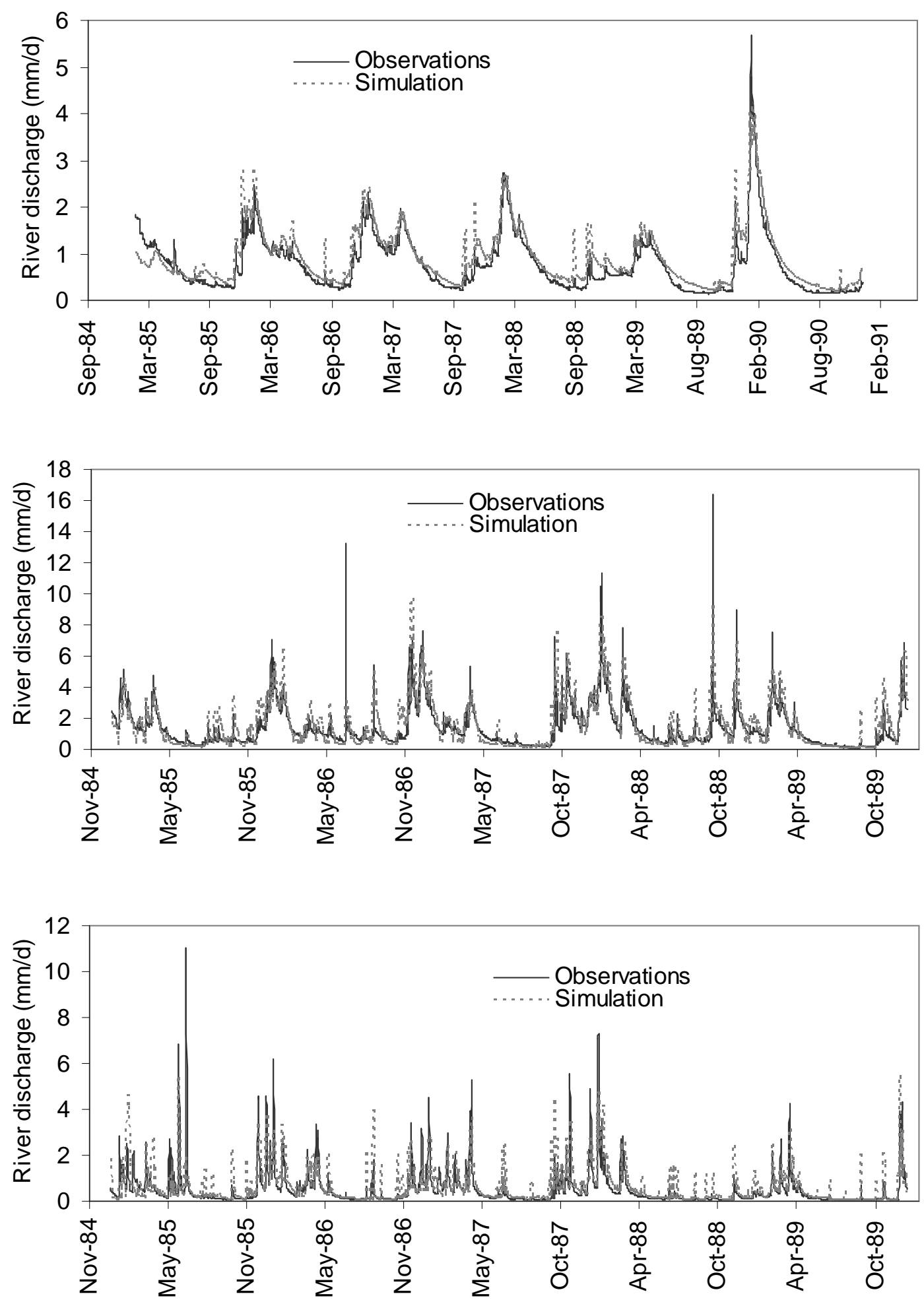

Figure 8 

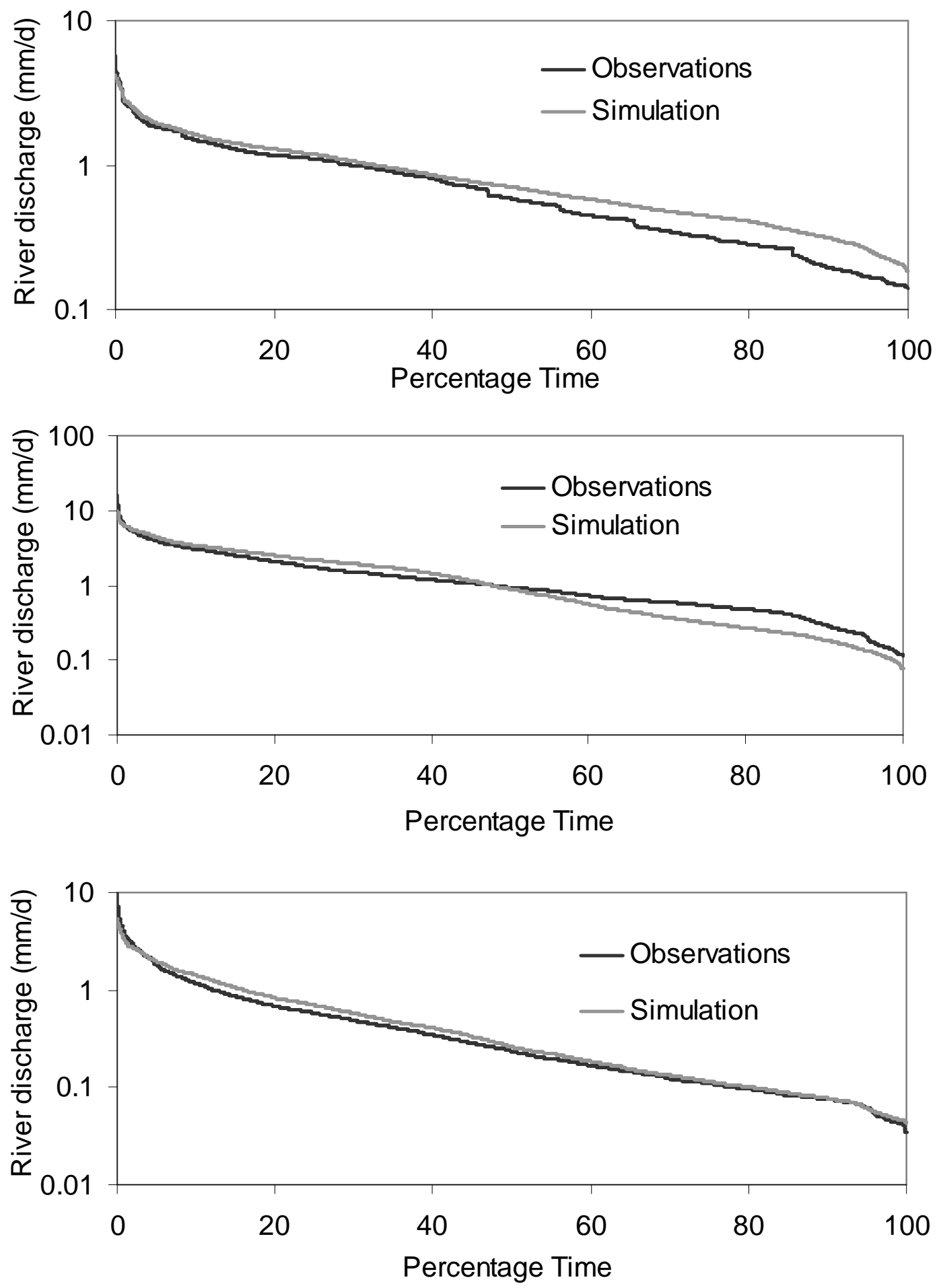

Figure 9 